\title{
Portal hypertension and bleeding ileal varices after colectomy and ileostomy for chronic ulcerative colitis
}

\author{
A. D. CAMERON AND D. J. FONE
}

From the Green Lane Hospital, Auckland, New Zealand, and the Royal Melbourne Hospital, Melbourne, Australia

SUMMARY Two patients are described with chronic liver disease and portal hypertension in association with ulcerative colitis for which colectomy and ileostomy had been performed. Both patients developed bleeding from the varices situated around the ileostomy stoma and one also bled from the oesophageal varices. Each had a successful portacaval shunt performed because of this bleeding.

The occurrence of such ileal varices is uncommon, but is important as a manifestation of portal hypertension. Although it can usually be easily controlled by local measures, portalsystemic shunt should always be considered, particularly as such patients are also very likely to bleed from oesophageal varices.

It is well recognized that chronic liver disease occurs in some patients with non-specific ulcerative colitis. Various types of liver disease have been reported including fatty infiltration, cirrhosis, chronic active hepatitis, and pericholangitis. In a recent review based upon histological study of liver biopsy specimens taken during life, Mistilis and Goulston (1965) found a minimal incidence of liver disease of almost $10 \%$, and also found that pericholangitis was the most common histological type. It is also known that some of these patients develop portal hypertension and may bleed from oesophageal varices. Liver disease is thus an important association or complication of ulcerative colitis, and may introduce some important considerations into the management of these patients.

In this paper we report on two patients with chronic liver disease and ulcerative colitis for which colectomy and ileostomy had been performed; both patients later developed portal hypertension and bled from varices situated at the ileostomy. This appears to be a rare occurrence, but one which it is important to recognize and which has certain therapeutic implications. Both patients had a portacaval shunt which to date has successfully prevented further bleeding. Received for publication 14 December 1969.

\section{Case Records}

\section{CASE 1}

Mrs J.K. first developed symptoms of ulcerative colitis in 1935 at the age of 21 , but she did not seek medical attention for this until 1960 as the disease remained relatively mild. She then had a severe exacerbation, with anaemia, oedema, ascites, and hepatosplenomegaly; cirrhosis was first diagnosed at this time. Management was complicated by her refusal to have any blood transfusion on religious grounds. Following further deterioration, a two-stage proctocolectomy was performed in 1963 by Mr Stanley Wilson at the Dunedin Public Hospital. An enlarged, finely nodular cirrhotic liver was noted, but no biopsy taken. Her general condition improved with the disappearance of the ascites and oedema.

In 1964 she first developed bleeding from the mucocutaneous junction of the ileostomy. This was initially an intermittent oozing, and was considered to be associated with the excoriated skin. Varicosities slowly appeared, and bleeding became more profuse.

In 1965 she again developed anaemia and oedema, and there was further ileostomy bleeding. The ileostomy stoma was amputated and the 


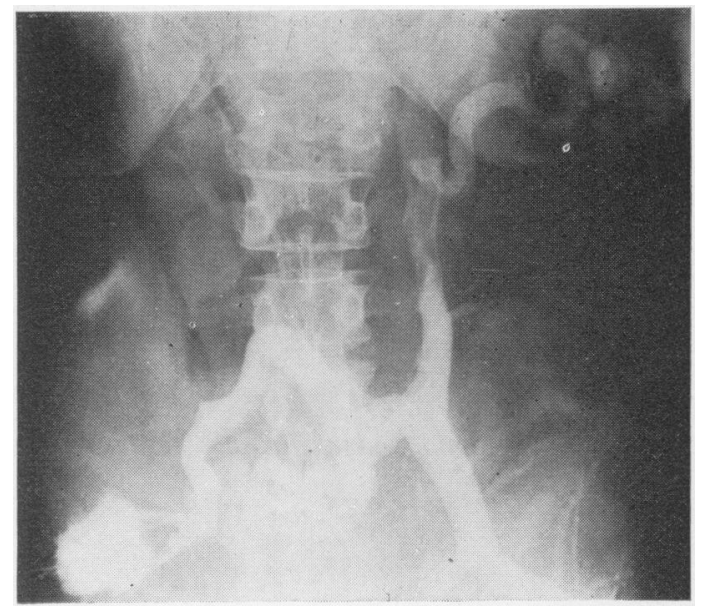

Fig. 1 Case 1. Splenoportogram showing large anastomotic vein running down to the ileostomy.

\begin{tabular}{lcc}
\hline Test & $\begin{array}{l}\text { Before } \\
\text { Operation }\end{array}$ & $\begin{array}{l}\text { Six Months } \\
\text { after Operation }\end{array}$ \\
\hline Haemoglobin (g\%) & $8 \cdot 3$ & $13 \cdot 4$ \\
BSR (mm/hr) & 2 & \\
Serum bilirubin (mg \%) & $1 \cdot 2$ & $2 \cdot 2$ \\
Total serum proteins (g\%) & $6 \cdot 4$ & $6 \cdot 4$ \\
Serum albumin (g\%) & $3 \cdot 2$ & $3 \cdot 8$ \\
Serum globulin (g\%) & $3 \cdot 2$ & $2 \cdot 6$ \\
SGOT (units) & 74 & 200 \\
Serum alkaline phosphatase (KA & 45 & 49 \\
$\quad$ units) & 45 & $12 \cdot 8$ \\
Zinc sulphate turbidity (units) & 14 & \\
BSP retention (\% in 45 min) & $24 \cdot 6$ & \\
Prothrombin concentration (\%) & 100 & \\
\hline
\end{tabular}

Table I The results of the investigations in case 1

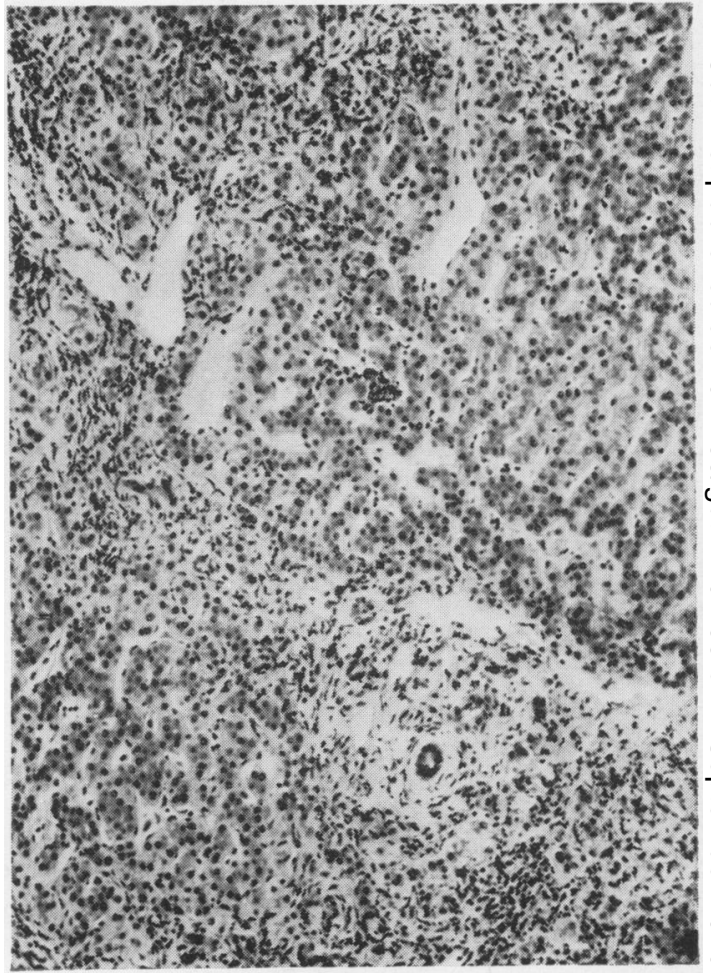

Fig. 2 Case 2. Liver biopsy showing increased fibrosis and cellularity of the portal tracts.
Table II The results of the investigations in case 2

varices were undersewn. Six months later further varicosities appeared at the mucocutaneous junction and periodic profuse bleeding occurred, which could usually be controlled by prolonged pressure by doctor or patient.

In August 1966 she was referred to Green Lane Hospital, Auckland. The liver was enlarged $8 \mathrm{~cm}$ and the spleen $10 \mathrm{~cm}$ below the costal margins. There was no jaundice and no spider naevi. Barium swallow revealed oesophageal varices. Splenoportography demonstrated an intrasplenic pressure of $400 \mathrm{~mm}$ of water and a dilated superior mesenteric vein shunting with abdominal wall veins at the site of the ileostomy

A side-to-side portacaval anastomosis was performed by $\mathrm{Mr}$ B. G. Barrett-Boyes, with immediate disappearance of the ileostomy varices. Blood transfusion was again not permitted. Liver biopsy was not performed because of the risk of bleeding, and a subsequent percutaneous needle biopsy produced only small fragments of liver tissue showing considerable fibrosis. The results of the relevant biochemical tests are given in Table I. The patient recovered well after operation. There has been no recurrence of the (Fig. 1). 
varices and no further ileostomy bleeding. There was no evidence at any stage of portalsystemic encephalopathy.

\section{CASE 2}

Mrs G.B. is at present aged 35 years. Symptoms of chronic ulcerative colitis commenced at the age of 13 , and continued intermittently until she was 26 . Then her symptoms became worse, she required blood transfusion, and was admitted to the Royal Melbourne Hospital. In November 1958 colectomy and ileostomy were performed by $\mathrm{Mr}$ Julian Orme Smith, the rectum being retained. For more than two years she remained well, though she continued to discharge bloodstained contents from the rectal stump. It had been intended to remove this stump as a secondstage procedure, but she failed to return to the hospital.

In August 1961 she became jaundiced for the first time. She was found to have an enlarged, slightly tender liver, but no splenomegaly, spider naevi, or other signs of chronic liver disease. Apart from the jaundice she looked and felt well. The results of relevant investigations at this time are shown in Table II. Liver biopsy showed a marked increase in celullarity and fibrosis in the portal tracts, which in many areas extended between the lobules, completely encircling some. The infiltrating cells were mainly lymphocytes, histiocytes, and plasma cells, but some polymorphs were also present. In some places the infiltrating cells and fibrous tissue had a circumductal distribution. There was no increase in number of bile ducts and no bile plugging (Fig. 2).

In January 1962 the excision of the rectum which had previously been planned was performed by Mr Graham McKenzie; laparotomy at the time revealed a normal biliary system without any apparent obstruction.

For more than two years the clinical condition remained unaltered, and the mild obstructive jaundice persisted with only minor fluctuations (Table II). In November 1964 she was again admitted to hospital, on this occasion because of bleeding from the margin of the ileostomy stoma. She also had cutaneous bruises, and a large haematoma developed in the floor of the mouth. The prothrombin concentration was $39 \%$ of a normal control. Vitamin $\mathbf{K}$ was administered, she was transfused, and all bleeding ceased. During this period jaundice became rather deeper (the serum bilirubin increasing to 6.1 $\mathrm{mg} \%$ ) and remained so thereafter.

In September 1965 she again bled from the ileostomy stoma; bleeding recurred on three occasions during the next six months. It was controlled by local sutures, blood transfusions, and vitamin $\mathrm{K}$. The bleeding occurred from several sites externally near the base of the stoma and near the mucocutaneous junction. It was thought that the flange of the ileostomy bag might have been causing irritation and either aggravating or precipitating the bleeding, and in February 1966 the ileostomy was refashioned. The skin around the ileostomy was a dusky blue colour, and a number of small tortuous veins were visible. At this operation $\mathrm{Mr}$ A. B. G. Carden noted many congested and tortuous veins in the subcutaneous layer about the ileostomy. The pressure was measured in one of these to be $500 \mathrm{~mm}$ of water. As far as possible, these veins were ligated and disconnected from the ileostomy.

The spleen had now become palpable for the first time. A barium swallow and meal did not reveal any radiological evidence of oesophageal varices, and no bleeding had occurred from within the gut up to this stage. Since the frequent recurrence of bleeding was now taken to be a manifestation of portal hypertension, a portalsystemic venous shunt was carefully considered but decided against for reasons which will be discussed later.

A few days later, she had her first haematemesis and melaena. Bleeding continued from the upper gastrointestinal tract for seven days, although at no stage was it massive or very profuse. Intravenous lysine vasopressin was administered on several occasions, with an apparent temporary reduction in bleeding. Balloon tamponade with the Sengstaaken Blakemore bag was attempted, also with apparent control of the bleeding for about 18 hours. At this stage she had received 34 pints of blood, and bleeding continued. She had remained quite alert throughout with no signs of hepatic encephalopathy. Examination of the oesophagus and stomach with the Eder fibrescope revealed oesophageal varices, although they were not seen to be actually bleeding at the time. It was decided that the portacaval shunt, deferred only two weeks previously, should now be performed.

Laparotomy was performed by Mr Graham McKenzie. The liver was scarred, nodular, and enlarged. The portal venous pressure was measured to be $450 \mathrm{~mm}$ of water. The portal vein was patent, and an end-to-side portacaval anastomosis was performed.

The patient recovered rapidly and there was no further bleeding. She did not develop any evidence of encephalopathy-she had remained alert and cheerful throughout the postoperative period. There was a slight increase in ascites, easily controlled by diuretic therapy. She was discharged from hospital two weeks after operation, taking a full diet, and with a normal electroencephalogram.

Mrs G.B. has remained well since, with no recurrence of bleeding from the ileostomy or the upper gastrointestinal tract. The depth of jaundice increased in the period immediately after operation, reaching $18 \mathrm{mg} \%$, but later decreased, although not quite to the preoperative level. It 
has fluctuated since, and has remained higher than previously. The other liver function tests have shown a general deterioration, although the rate of change has remained slow (Table II).

\section{Discussion}

Both these patients suffered bleeding from venous channels around the mucocutaneous junction of an ileostomy, which we believe occurred as a result of portal hypertension. This area in such a patient represents an abnormal communication between the high pressure portal venous system and the lower pressure systemic system, and varices may develop in the same way as at the oesophago-gastric junction, at the site of adhesion of abdominal organs to previous laparotomy scars (Sherlock, 1958), or at the anastomosis following colonic bypass performed for chronic hepatic encephalopathy (Resnick, Ishihara, Chalmers, Schimmel, and the Boston InterHospital Liver Group, 1968). Our main purpose in recording these two cases is to draw attention to this uncommon manifestation of portal hypertension and to comment on its significance and management. It is of particular importance when the incidence of chronic liver disease in ulcerative colitis is considered.

It was initially thought in these cases that the bleeding was caused by local irritation and trauma, perhaps from the flange of the ileostomy appliance. In both cases local surgical procedures were performed in attempts to control this (amputation of the stoma in case 1, and refashioning in case 2 ). This provided only temporary benefit, though in case 2 the procedure did provide the information of the presence of portal hypertension. The bluish discoloration of the skin surrounding the ileostomy as seen in both patients should also help to indicate the true significance of the bleeding.

Careful consideration was given to the place of surgical treatment for this ileostomy bleeding, and in particular to whether a portal systemic shunt should be performed because of it. It was initially thought that this was not an indication for such a shunt, a major reason being that the bleeding was external, from a visible site, and could be controlled by local measures including pressure, ligation, cautery, or if necessary a rather more extensive venous disconnection of the stoma, as was indeed performed in case 2 . We would still adhere to this general view, at least in the earlier stages, but our observations of the later course of both patients have led us to modify this belief. First the bleeding, though usually relatively easily controlled, may recur frequently, or it may become severe and difficult to control. Second, when such bleeding is occurring it is quite likely that the patient also has oesophageal varices, though they may be difficult to demonstrate. Both our patients had oesophageal varices, as did all three patients described by Resnick et al (1958); in these patients stomal varices occurred following colonic $\overrightarrow{\overline{\vec{F}}}$ bypass. For these reasons we believe that this type of ileostomy bleeding should be regarded as a likely manifestation of portal hypertension, that oesophageal varices are also likely to be present, and that procedures to reduce the portal pressure should be carefully considered.

A feature of considerable interest and practical importance in management was the absence of clinical portal-systemic encephalopathy in circumstances where this would have been expected. It would appear that the absence of the colon in both patients was a significant factor contributing towards this, and should be taken into con- 0 sideration in the treatment of patients who have previously undergone total colectomy. The role of the colon in the development of hepatic $\triangle$ coma and portal systemic encephalopathy is $\overrightarrow{0}$ well established. Colectomy or colonic exclusion may reduce or abolish the neuropsychiatric $\frac{0}{\mathbb{D}}$ manifestations of chronic liver failure. Experi- 3 mentally it has been shown that such proce- 旡 dures may protect a dog from development of encephalopathy following portal systemic shunt procedures.

It is not surprising therefore that a patient with an ileostomy and total colectomy should be at less risk than the patient with an intact intestinal canal, and this appeared to be so in our two patients. In the earlier management of both patients the probable risk of encephalopathy had been considered important in the decision not to perform shunt surgery. Later, however, the very absence of such encephalopathy after massive haemorrhage, despite liver function that appeared to be far from ideal, was then a source of encouragement to proceed to portacaval anastomosis.

From our clinical observations of these two patients, we have little doubt that the absence of the colon played a significant role in protecting them against hepatic encephalopathy. We believe this should be properly considered when planning the treatment of such patients. It should be of remembered, however, that colectomy does not $N$ completely protect the patient against encephalo- N pathy. Chapman and Janowitz (1966) have described a patient with an ileostomy in whom the lower ileum contained bacteria similar to those normally resident in the colon. Their patient $\stackrel{?}{\rightarrow}$ developed liver failure, relieved by antibiotic 0 sterilization of the ileum. Thus it appears that bacterial invasion of the ileum may occur after ileostomy in sufficient degree to lead to hepatic failure-at least in some patients-but it is probable that such patients are at much less risk than those with normal intestinal continuity.

The nature of the liver disease in these two patients is of interest. In case 1 this remains obscure as there has been no adequate 
material available for histological examination. In case 2 early liver biopsies showed features consistent with chronic pericholangitis (Mistilis, 1965) and later, with a well established cirrhosis. Mistilis and Goulston (1965) reported that five of 23 patients with chronic pericholangitis progressed to the development of cirrhosis, and three of them developed portal hypertension, as did two others in the absence of cirrhosis. They state that the course and progression of this type of liver disease does not bear any direct relationship to the 'activity' of the colitis and is apparently not affected by removal of the colon. They do not refer to any instance of pericholangitis developing after colectomy, as occurred in case 2 in our series. There are two possible explanations of this occurrence. First, the rectum had not been removed, and may have acted as the 'cause' of the liver disease, and in this respect it is interesting to speculate whether the liver disease may have been avoided if the rectum had been excised when originally planned. Second, pericholangitis may remain clinically asymptomatic for long periods. This may have been so in our second case for a period before the onset of jaundice and it may have been present before the colectomy; we have no records of biochemical liver function tests before the onset of the jaundice.

Whatever the exact nature of the liver disease, it appears probable that it has been causally related to the ulcerative colitis. Furthermore it has progressed to cirrhosis and portal hyper- tension with severe gastrointestinal haemorrhage from ileal varices as well as from oesophageal varices. We report these two cases to stress the occurrence of severe liver disease in ulcerative colitis, that it may become clinically apparent after removal of the colon, and finally to draw attention to the unusual development of ileal varices as a major manifestation of portal hypertension.

We should like to acknowledge the part played in the medical care of these patients by their medical practitioners, Dr J. J. O'Hagan at Invercargill, New Zealand, and $\mathrm{Dr}$ H. M. Pannifex at Bendigo, Victoria, Australia.

\section{References}

Chapman, M., and Janowitz, H. D. (1966). Chronic portalsystemic encephalopathy after ileostomy and colonic resection. Lancet, 1, 1064-1066.

Mistilis, S. (1965). Pericholangitis and ulcerative colitis. I. Pathology, aetiology and pathogenesis. Ann. intern. Med., 63, 1-16.

Mistilis, S. P., and Goulston, S. J. M. (1965). Liver disease in ulcerative colitis. In Recent Advances in Gastroenterology, edited by J. Badenoch and B. Brooke, pp. 27-247. Churchill, London.

Resnick, R. H., Ishihara, A., Chalmers, T. C., Schimmel, E. M., and the Boston Inter-Hospital Liver Group. (1968). A controlled trial of colon bypass in chronic hepatic encephalopathy. Gastroenterology, 50, 1057-1069.

Sherlock, S. (1958) Diseases of the Liver and Biliary System, 2nd ed. Blackwell, Oxford. 